\title{
Propagandas de serviços médicos especializados na internet: aspectos bioéticos envolvidos nessa questão
}

Advertising of specialized medical services in the internet: bioethical aspects involved in the matter

Propagandas de servicios médicos especializados en el internet:

aspectos bioéticos envueltos en esa cuestión

\section{Marco Antonio Mendes Rocha ${ }^{1}$}

- Acadêmico do $6^{\circ}$ ano de Medicina da Pontifícia Universidade Católica de Campinas (Puccamp)

- E-mail: marcomed38@yahoo.com.br

\section{Paulo Roberto de Sousa}

- Doutor em Clínica Médica pela Universidade Estadual de Campinas (Unicamp)

- Professor titular de Deontologia Médica da Faculdade de Medicina da Puccamp

- E-mail: profpaulosousa@gmail.com

\section{José Espin Neto}

- Doutor em Saúde da Criança e do Adolescente pela Unicamp

- Professor titular de Pediatria da Faculdade de Medicina da Puccamp

- E-mail: espin@sigmanet.com.br

\section{Lenamaris Mendes Rocha}

- Médica-residente do Hospital de Clínicas da Unicamp

- E-mail: lena@fcm.unicamp.br

\footnotetext{
${ }^{1}$ Este trabalho foi realizado na Faculdade de Medicina e Ciências da Vida, da Pontifícia Universi-dade Católica de Campinas (Puccamp), com bolsa do Centro de Bioética do Conselho Regional de Medicina do Estado de São Paulo (Cremesp), concedida ao autor Marco Antônio Mendes Rocha. Foi orientado pelo coautor Prof. Dr. Paulo Roberto de Souza, com a co-orientação do coautor Prof. Dr. José Espin Neto e a colaboração da coautora Dra. Lenamaris Mendes Rocha.
} 


\section{Resumo}

Propaganda médica é tema de relevância mundial controverso. O médico tem legítimo direito de propagar suas atividades profissionais, mas deve conservar-se dentro dos limites éticos. É clara a importância que a comunicação assume na promoção da saúde. A internet insere-se, nesta conjuntura, como uma mídia utilizada para educação da população e propagação da publicidade médica. Contudo, o compromisso ético vem sendo substituído por interesses da política socioeconômica capitalista. Quando o médico se torna responsável pela banalização da medicina, coloca em xeque a relação médico-paciente. Este estudo levantou no Google propagandas de serviços médicos especializados do Estado de São Paulo na internet, de outubro de 2008 a julho de 2009.

\section{PALAVRAS CHAVE: PUBLICIDADE • INTERNET • ÉTICA MÉDICA • BIOÉTICA}

\section{Abstract}

Medical advertising is a controversial theme of worldwide relevance. The physician has the legitimate right of advertising his/her professional activities, but must preserve him/herself within the ethical limits. The importance that communication assumes in the promotion of health is clear. The internet is inserted in this conjuncture as a media used for education of the population and dissemination of medical advertising. However, the ethical commitment is being substituted by capitalist socioeconomic political interests. When the physician becomes responsible for the trivialization of medicine, it challenges the physician-patient relationship. This study assessed, in Google, advertisements of specialized medical services of the State of São Paulo in the internet, from September 2008 to July 2009.

\section{KEYWORDS: ADVERTISING • INTERNET • MEDICAL ETHICS • BIOETHICS}

\section{Resumen}

La propaganda médica es un tema controversial de relevancia mundial. El médico tiene el legítimo derecho de propagar sus actividades profesionales, pero debe conservarse dentro de los límites éticos. Está clara la importancia que la comunicación asume en la promoción de la salud. El internet se insiere, en esta coyuntura, como un medio utilizado para educación de la población y propagación de la publicidad médica. A pesar de eso, el compromiso ético viene siendo substituido por intereses de la política socioeconómica capitalista. Cuando el médico se torna responsable por la banalización de la medicina, se coloca en jaque la relación médico-paciente. Este estudio procuró en Google propagandas de servicios médicos especializados del Estado de São Paulo en el internet, de octubre de 2008 a julio de 2009.

PALABRAS CLAVE: PUBLICIDAD • INTERNET • ÉTICA MÉDICA • BIOÉTICA 
A propaganda é uma maneira de se apresentar e divulgar uma informação. A palavra latina propaganda, tem o sentido de "aquilo que precisa ser espalhado" (Alcântara, 1984, p. 517). A informação é fundamental para qualquer ramo da atividade profissional e a medicina não é diferente das demais profissões nesse aspecto. Os meios de comunicação de massa têm um papel importante de informar a população sobre a prevenção de enfermidades e problemas de saúde, fornecendo subsídios para avaliação das opções de tratamento e tomada de decisões (Machado, 2006, p. 7-14). A questão fundamental é como o médico deve proceder de modo a exercer seu legítimo direito de propagar as atividades profissionais, conservando-se dentro dos limites éticos (Simoneli, 2006, p. 33-38).

Este tema foi abordado no Código Internacional de Ética Médica, adotado em outubro de 1949 pela terceira assembleia geral da World Medical Association (WMA), realizada em Londres, quando foram estabelecidos os deveres do médico e que qualquer publicidade deve respeitar as leis do país e as resoluções do Código de Ética Médica (WMA, 1949). A publicidade médica continua sendo tema de relevância mundial. "Publicidade médica é a comunicação ao público por qualquer meio de divulgação, de atividade profissional de iniciativa, participação e anuência do médico" (Cremesp, 2003).

A internet insere-se como ferramenta importante para a educação, a promoção da saúde e, também, a publicidade médica, pois é um dos meios de comunicação de massa mais ágeis e difundidos, modificando a forma de oferecer e receber informações sobre saúde. Qualquer pessoa pode criar um site e disponibilizar informações a todos a partir dessa mídia, devido à facilidade cada vez maior da criação de criação de páginas na web (Perche, 2006, p. 43-45)..Por meio da internet, o médico poderá não só anunciar, mas também ensinar o que é sua especialidade, quais as doenças que são tratadas, sua prevenção e formas de tratamentos possíveis, o que seria muito mais limitado e oneroso em outras mídias (Antunes; França, 2000, p. 117-122).

Contudo, em muitos casos, a internet tornou-se um veículo de publicidade enganosa na área médica. A questão não é mais conseguir a informação, mas definir a credibilidade do autor e a relevância do documento disponível na rede. As poucas legislações existentes não conseguem disciplinar a dinâmica dessa mídia global. A comunidade internauta tem grande resistência em atender regulamentações governamentais e não existe um consenso jurídico sobre a disponibilização de informações ou a prestação de serviços de saúde on-line (Perche, 2006).

Partindo da necessidade de controlar o número crescente de denúncias registradas do exercício antiético da medicina em relação à publicidade médica, a Comissão de Divulgação Assuntos Médicos (Codame), um órgão do Conselho Regional de Medicina do Estado de São Paulo (Cremesp), criou o manual Ética em publicidade médica (Cremesp, 2006). Nesse manual, o Codame publicou um capítulo, "Internet e publicidade médica", sobre princípios éticos para sites de medicina e saúde na rede mundial de computadores. 
Os médicos que utilizam a internet estão obrigados a seguir as normas do Codame e a resolução n. 97, de 20/02/2001, do Cremesp (Cremesp, 2001). Também devem ser cautelosos ao divulgar descobertas, novas técnicas e/ou tratamentos, por intermédio de canais não profissionais. Poderá ser punido pelo Conselho Regional de Medicina (CRM) o médico que utilizar a internet para autopromoção com vistas a aumentar sua clientela; fazer concorrência desleal, como promoções no valor de consultas e cirurgias; pleitear exclusividade de métodos diagnósticos ou terapêuticos; fazer propaganda de determinado produto, equipamento ou medicamento, em troca de vantagem econômica oferecida por empresas ou pela indústria farmacêutica (Perche, 2006).

O Codame, com base na resolução n. 1.701/03, do Conselho Federal de Medicina (CFM), estabelece que no anúncio médico só é permitido pôr o nome do profissional, com respectivo número de inscrição no CRM de sua jurisdição, especialidades (duas no máximo), desde que devidamente registradas no conselho, títulos científicos e dados referentes à sua localização (endereço e telefone). Nos anúncios de clínicas, hospitais, casas de saúde, entidades de prestação de assistência médica e outros estabelecimentos de saúde, deverão constar, sempre, o nome do médico diretor técnico e sua inscrição principal no CRM em cuja jurisdição se encontrar o estabelecimento de saúde (CFM, 2003, p. 171-172).

Os médicos também têm a liberdade de informação disciplinada pelo Código de Ética Médica e devem obediência a uma legislação, civil e criminal, que objetiva tanto fiscalizar como penalizar os que abusam do direito de informar (Pereira Filho, 2006, p. 17-18), conforme o capítulo XIII do Código de Ética Medica (CFM, 1988, p. 1.574-1.577) e a Lei Federal n. 4.680 (Brasil, 1965).

\section{A QUESTÃO DA PROPAGANDA MÉDICA}

O Conselho Nacional de Autorregulamentação Publicitária (Conar) tem a responsabilidade de garantir que a publicidade seja veiculada em conformidade com a ética e as leis. Ele julga do ponto de vista da ética publicitária, sustando anúncios ou recomendando alterações para que eles se adaptem às normas éticas, não encaminhando essas questões a promotorias públicas ou delegacias do consumidor (Conar, 1978). O Código de Defesa do Consumidor (CDC) sedimentou quatro princípios específicos da publicidade, sob o aspecto da defesa do consumidor: 1. veracidade; 2. clareza; 3. correção; 4. informação (Brasil, 1990);

A questão é que, quando o médico deixa de obedecer aos preceitos éticos, passa a ser responsável pela banalização da medicina. Os artigos $1^{\circ}$ e $2^{\circ}$ do capítulo I - Princípios fundamentais do Código de Ética Médica definem que "a medicina é uma profissão a serviço da saúde do ser humano e da coletividade e deve ser exercida sem discriminação de qualquer natureza" (CFM, 1988, p. 1.574-1.577). 
Percebe-se que se está diante de uma situação a ser evitada em sua essência, pois se corre o risco de as entidades e a maioria da classe médica sofrerem graves consequências com a mercantilização da medicina praticada por esses profissionais e por alguns veículos de informação irresponsáveis, os quais não têm qualquer compromisso com o ser humano e com a ética (Camarim, 2006, p. 15-16).

A divulgação de novas técnicas diagnósticas e terapêuticas, desconhecidas até então pela população, é um dos aspectos mais positivos da publicidade médica (Pereira Filho, 2006, p. 17-18). Outro aspecto que não deve ser esquecido é que a publicidade pode (e deve) ter um efeito educativo para quem recebe a informação. A publicidade médica que veicula novos conhecimentos, com propósito educativo ao público, será sempre uma propaganda positiva e não meramente promocional de quem anuncia (Favero, 1930, p. 302).

A publicidade também tem aspectos positivos para o profissional médico. É por intermédio da propaganda que ele pode informar o que faz, onde faz, em que horário trabalha e como pode ser encontrado. Fazer-se conhecer e oferecer seus serviços à comunidade são, sem dúvida, aspectos positivos para o médico (Pereira Filho, 2006, p. 17-18).

Neste ponto reside o conflito discutido nesta pesquisa: o compromisso ético, que é fundamental para o anúncio adequado, vem sendo substituído por interesses da política socioeconômicas neoliberais, cujo principal objetivo está centrado na obtenção do lucro. A conquista do mercado por estratégias da utilização da mídia e, principalmente, da internet, vem se tornando uma constante. A "lei da oferta e da procura" é o princípio básico da economia neoliberal vigente, que regula os preços do mercado. Acreditava-se que certas formas de interferência governamental na economia eram aceitáveis, caso se destinassem a prevenir injustiça e opressão ou incentivar a educação e proteger a saúde pública (Motta; Braick, 1997, p. 254-258).

A lei de mercado ainda se faz presente. Na medicina vem sendo responsável pela mercantilização do serviço médico. Há uma imensa quantidade ("oferta") de propagandas médicas desregulamentadas oferecidas pelos sites. Neste aspecto, a competitividade e a livre concorrência colocam em risco a relação médico-paciente (Machado, 2006, p. 7-14). A consequência da desestruturação da relação médico-paciente é a formação de uma mentalidade tecnicista. Na prática, o médico acaba por encarar o corpo humano como uma máquina e suas desordens (as doenças), como situações decorrentes de desarranjos anatômicos, fisiológicos ou bioquímicos, de origem genética ou adquirida, passíveis então de uma abordagem terapêutica voltada apenas ao organismo físico. Por outro lado, o paciente deixa de participar ativamente do processo de reabilitação (Crema, 1995).

Essa mentalidade negligencia o conceito de saúde, que está relacionado ao bem-estar físico, psíquico e social do ser humano. Para conquistar um bom relacionamento, portanto, alguns 
fatores são fundamentais na relação médico-paciente, tais como: segurança, validação, aceitação, confirmação da experiência pessoal, autodefinição, impacto sobre a outra pessoa e iniciativa (Crema, 1995).

A propaganda é uma ferramenta importante da comunicação, que pode e deve ser utilizada pela medicina. O médico deve saber valer-se dela para a promoção da saúde, sempre priorizando os princípios éticos. Caso contrário, passa a ser o grande responsável pela banalização de sua profissão ao sobrepor os interesses capitalistas aos limites da bioética (Silva, 2001).

\section{PESQUISA DA PROPAGANDA MÉDICA NA INTERNET}

Este estudo levantou no Google propagandas de serviços médicos especializados do Estado de São Paulo na internet, de outubro de 2008 a julho de 2009. Na sequência, os objetivos visados com a pesquisa.

\section{Objetivos}

Nossa pesquisa sobre as propagandas médicas na internet tiveram como como objetivos básicos:

- Fazer um levantamento das propagandas de serviços médicos especializados, do Estado de São Paulo, na internet, de maio de 2008 a fevereiro de 2009;

- Analisar quais especialidades médicas utilizam a internet para veicular suas propagandas e realizar um gráfico com as áreas da medicina que mais se beneficiam desse meio de comunicação;

- Identificar quais serviços médicos especializados do Estado de São Paulo seguem as normas do Codame para realização de suas propagandas;

- Detectar os pontos positivos e negativos presentes nas propagandas médicas realizadas na internet;

- Avaliar quais artigos do Código de Ética Médica e quais normas do Codame são infringidos pelas propagandas médicas realizadas na internet.

\section{Metodologia}

Realizou-se a pesquisa de propagandas de serviços médicos especializados pelo site Google da web no período de outubro de 2008 a julho de 2009. Esse site funciona sobre uma combinação única de avançados hardware e software. Tem um algoritmo de busca em rede e mecanismo bastante eficiente. Possui um sistema para dar notas para páginas na web, desenvolvido pelos fundadores 
Larry Page e Sergey Brin na Universidade de Stanford (EUA). Além disso, é um site bastante difundido no Brasil, que engloba uma parcela considerável das propagandas realizadas na internet. No primeiro momento, foram utilizadas para a busca as seguintes palavras-chave: "serviços médicos especializados", "propagandas médicas", "publicidade médica" e "serviços médicos na internet".

Foram incluídos neste estudo os sites do Google que estavam entre as páginas do Brasil disponíveis na busca e que se voltavam para a divulgação de serviços médicos especializados no Estado de São Paulo. Encontraram-se aproximadamente 3.460 .000 sites que correspondiam aos descritores utilizados na busca pela internet, porém, apenas duzentos eram sites médicos dedicados à divulgação de serviços médicos especializados no Estado de São Paulo, tendo sido esse o critério de inclusão naa pesquisa.

Foram excluídos os sites de planos de saúde, hospitais, policlínicas e cooperativas médicas.

No Estado, os médicos que utilizam a internet são obrigados a seguir a resolução n. 97, de 20/02/2001, do Cremesp, e as normas do Codame. Sendo assim, em um segundo momento, analisou-se a qualidade dos sites e se estes estavam comprometidos com os princípios éticos. Para tanto, usou-se o manual do Codame, Ética em publicidade, de 2006. Neste existe um capítulo "Internet e publicidade médica", sobre princípios éticos para sites de medicina e saúde na rede mundial de computadores e um capítulo, "Guia prático", que oferece respostas às principais dúvidas dos médicos para a elaboração de propagandas. Ambos foram utilizados para o estabelecimento dos critérios que consideramos na avaliação dos sites.

\section{Categorização}

As propagandas foram classificadas em dois grupos: grupo A, que reuniu aquelas realizadas segundo as normas do Codame consideradas nesta pesquisa e, consequentemente, segundo o Código de Ética Médica; e grupo B, que continha as propagandas de serviços médicos especializados que não seguiam as normas do Codame. Das normas consideradas nesta pesquisa, foram utilizadas aquelas que permitiam uma avaliação objetiva da propaganda do serviço médico especializado no Estado de São Paulo. Na sequência, reproduzimos literalmente essas normas:

As propagandas médicas na internet devem conter: o nome do profissional, com respectivo número de inscrição no CRM de sua jurisdição, as especialidades (duas no máximo), títulos científicos e dados referentes à sua localização (endereço e telefone).

Os anúncios de clínicas, hospitais, casas de saúde, entidades de prestação de assistência médica e outros estabelecimentos de saúde devem conter o nome do médico diretor técnico ou responsável e sua inscrição principal no CRM em cuja jurisdição se encontrar o estabelecimento de saúde. 
- $\quad$ As propagandas não devem ter promoções com os valores de consultas e/ou cirurgias.

- Os médicos não devem pleitear exclusividade de métodos diagnósticos ou terapêuticos.

- Em sites dirigidos ao público leigo, não deve haver a transmissão de cirurgias em tempo real ou não.

- Os médicos não podem publicar ou expor fotos do pré e do pós-operatório de pacientes na internet.

- $\quad$ Nas propagandas médicas não deve haver exposição pública de pacientes, por meio de fotos e imagens.

- Não se deve fazer referência a casos clínicos identificáveis, exibir pacientes ou seus retratos em anúncios profissionais ou na divulgação de assuntos médicos, à exceção das videoconferências.

- Os médicos podem prestar informações, dar entrevistas e publicar artigos versando sobre assuntos que sejam estritamente de fins educativos. Nesse tipo de divulgação, os médicos devem ser identificados e ter seu número de inscrição no conselho profissional aposto no corpo do anúncio. Não devem divulgar, durante entrevistas, endereços e/ou telefones de consultórios.

- Existem ainda outras normas do Codame que devem ser seguidas pelo médico na elaboração das propagandas médicas. Mas estas não foram incluídas no presente estudo, em razão do caráter subjetivo e da dificuldade de análise dos resultados. Reproduzimo-las também literalmente, a seguir:

- As informações médicas veiculadas nos sites devem ser estritamente educativas e de esclarecimento da coletividade.

- Os médicos devem evitar o sensacionalismo nas propagandas realizadas e não devem utilizar a internet para autopromoção no sentido de aumentar a clientela e fazer concorrência desleal.

- Não devem fazer propaganda de determinado produto, equipamento ou medicamento, em troca de vantagem econômica oferecida por empresas ou pela indústria farmacêutica.

- Não devem pleitear exclusividade de métodos diagnósticos ou terapêuticos.

- Não devem participar de anúncios de empresas comerciais.

- Não devem prometer cura de doenças para as quais a medicina ainda não possui recursos e [nem] divulgar métodos, meios e práticas experimentais e/ou alternativas que não tenham reconhecimento científico. 
Os resultados foram analisados pelo programa XIstat09, que seguiu o modelo desta tabela:

Tabela 1 - Informações pesquisadas nos sites médicos

\begin{tabular}{|c|c|c|c|}
\hline \multirow{2}{*}{$\begin{array}{l}\text { Informações } \\
\text { pesquisadas }\end{array}$} & \multirow{2}{*}{$\frac{\text { Resposta }}{\text { Sim }}$} & \multicolumn{2}{|c|}{ Informações } \\
\hline & & Não & Site da pesquisa \\
\hline \multicolumn{4}{|l|}{01 - Nome } \\
\hline \multicolumn{4}{|l|}{02 - CRM } \\
\hline \multicolumn{4}{|l|}{03 - Especialidade } \\
\hline \multicolumn{4}{|l|}{04 - Títulos científicos } \\
\hline \multicolumn{4}{|l|}{05 - Endereço } \\
\hline \multicolumn{4}{|l|}{06 - Telefone } \\
\hline \multicolumn{4}{|l|}{$\begin{array}{l}07 \text { - Valores de } \\
\text { consulta e/ou cirurgia }\end{array}$} \\
\hline \multicolumn{4}{|l|}{$\begin{array}{l}08 \text { - Divulgação de exclusividade de } \\
\text { métodos diafnósticos }\end{array}$} \\
\hline \multicolumn{4}{|l|}{$\begin{array}{l}09 \text { - Divulgação de exclusividade de } \\
\text { métodos terapêuticos }\end{array}$} \\
\hline \multicolumn{4}{|l|}{$\begin{array}{l}10 \text { - Transmissão de cirurgias em } \\
\text { tempo real }\end{array}$} \\
\hline \multicolumn{4}{|l|}{$\begin{array}{l}11 \text { - Fotos do pré e } \\
\text { do pós operatório } \\
\text { dos pacientes }\end{array}$} \\
\hline \multicolumn{4}{|l|}{$\begin{array}{l}12 \text { - Fotos, retratos ou imagens dos } \\
\text { pacientes }\end{array}$} \\
\hline \multicolumn{4}{|l|}{$\begin{array}{l}13 \text { - Exposição pública dos pacien- } \\
\text { tes }\end{array}$} \\
\hline \multicolumn{4}{|l|}{$\begin{array}{l}14 \text { - Referência a } \\
\text { casos clínicos } \\
\text { identificáveis }\end{array}$} \\
\hline \multicolumn{4}{|l|}{$\begin{array}{l}15 \text { - Nos sites informativos que } \\
\text { possuem entrevistas e/ou artigos } \\
\text { publicados há identificação do } \\
\text { profissional }\end{array}$} \\
\hline \multicolumn{4}{|l|}{$\begin{array}{l}16 \text { - Nos sites informativos que pos- } \\
\text { suem entrevistas e/ou artigos publi- } \\
\text { cados há CRM do profissional }\end{array}$} \\
\hline $\begin{array}{l}17 \text { - Nos sites informativos que } \\
\text { possuem entrevistas e/ou artigos } \\
\text { publicados há divulgação de ende- } \\
\text { reços/telefones de consultórios nas } \\
\text { entrevistas do profissional }\end{array}$ & & & \\
\hline
\end{tabular}


Foi realizada ainda uma análise qualitativa partindo das especialidades médicas que utilizam a internet para veicular suas propagandas sem seguir as normas do Codame e infringindo, dessa forma, o Código de Ética Médica, além de uma análise qualitativa dos pontos positivos e negativos das propagandas médicas realizadas na internet.

\section{ANÁLISE DOS RESULTADOS}

Analisaram-se-se duzentos sites de propagandas de serviços médicos especializados do Estado de São Paulo, no período de outubro de 2008 a julho de 2009. Fez-se uma análise exploratória dos dados segundo frequências, porcentagens e construção de gráficos. O nível de confiança utilizado nas análises comparativas foi de $95 \%$ e o software estatístico utilizado foi o XLSTAT 2009. Pôde-se observar que:

- Dos 200 sites analisados, 11 (5,5\%) não apresentavam o nome do profissional médico responsável pela divulgação de seu serviço e 76 (38\%) não apresentavam o número de inscrição do CRM de sua jurisdição.

- Das propagandas, 8 (4\%) não especificaram para o público leigo a especialidade medica do profissional.

- Continham títulos científicos dos profissionais médicos $136(68 \%)$ das propagandas.

- $181(90,5 \%)$ propagandas médicas continham o endereço do profissional e $183(91,5 \%)$ possuíam telefone para contato.

- Valores das consultas estavam presentes em 3 (1,5\%) propagandas. Em 1 delas havia divulgação de exclusividade de método diagnóstico e em 6 (3\%) havia divulgação de exclusividade de método terapêutico.

- $\quad$ Promoveram exposição de pacientes 18 (9\%) propagandas médicas, sendo que: 3 apresentavam transmissão de cirurgia em tempo real; 2 continham fotos do pré e pós-operatório dos pacientes; 8 apresentavam fotos, retratos ou imagens dos pacientes; e 5 faziam referências a casos clínicos identificáveis.

- Entrevistas ou artigos publicados pelos profissionais estavam presentes em 10 (5\%) sites e todos estes apresentavam a identificação do profissional médico, porém apenas 3 continham o CRM do autor. Em 4 deles havia divulgação de endereços/telefones de consultórios.

- Dos 200 sites avaliados apenas 2 seguiam todas as normas do Codame.

As comparações entre os sites que seguiam as normas do Codame e os sites que não as seguiam foram realizadas por meio do teste de uma proporção e podem ser verificadas na tabela 2 e no gráfico 1 para cada critério avaliado. 
Tabela 2 - Frequências e porcentagens encontradas em relação aos critérios investigados nos sites médicos

\begin{tabular}{|c|c|c|c|c|c|}
\hline \multirow{2}{*}{$\begin{array}{l}\text { Informações } \\
\text { pesquisadas nos } \\
\text { sites médicos }\end{array}$} & \multicolumn{2}{|c|}{ Sim } & \multicolumn{2}{|c|}{ Não } & \multirow{2}{*}{ Total } \\
\hline & $\mathbf{n}$ & $\%$ & n & $\%$ & \\
\hline 01 - Nome & 189 & 94,5 & 11 & 55 & 200 \\
\hline 02 - CRM & 76 & 38,0 & 124 & 62,0 & 200 \\
\hline 03 - Especialidade & 192 & 96,0 & 8 & 4,0 & 200 \\
\hline 04 - Títulos científicos & 136 & 68,0 & 64 & 32,0 & 200 \\
\hline 05 - Endereço & 181 & 90,5 & 19 & 9,5 & 200 \\
\hline 06 - Telefone & 183 & 91,5 & 17 & 8,5 & 200 \\
\hline $\begin{array}{l}07 \text { - Valores de } \\
\text { consulta e/ou cirurgia }\end{array}$ & 3 & 1,5 & 197 & 98,5 & 200 \\
\hline $\begin{array}{l}08 \text { - Divulgação de exclusividade } \\
\text { de métodos diagnosticos }\end{array}$ & 1 & 0,5 & 199 & 99,5 & 200 \\
\hline $\begin{array}{l}09 \text { - Divulgação de exclusivida- } \\
\text { de de métodos tetapêuticos }\end{array}$ & 6 & 3,0 & 194 & 97,0 & 200 \\
\hline $\begin{array}{l}10 \text { - Trnasmissão de cirurgias } \\
\text { em tempo real }\end{array}$ & 3 & 3,4 & 84 & 96,6 & 87 \\
\hline $\begin{array}{l}11 \text { - Fotos do pré e pós-operató- } \\
\text { rio dos pacientes }\end{array}$ & 2 & 2,3 & 85 & 97,7 & 87 \\
\hline $\begin{array}{l}12 \text { - Fotos, retratos ou imagens } \\
\text { dos pacientes }\end{array}$ & 8 & 4,0 & 192 & 96,0 & 200 \\
\hline $\begin{array}{l}13 \text { - Exposição pública dos pa- } \\
\text { cientes }\end{array}$ & 18 & 9,0 & 182 & 91,0 & 200 \\
\hline $\begin{array}{l}14 \text { - Referência a casos clínicos } \\
\text { identificáveis }\end{array}$ & 5 & 2,5 & 195 & 97,5 & 200 \\
\hline $\begin{array}{l}15 \text { - Nos sites informativos que } \\
\text { possuem entrevistas e/ou artigos } \\
\text { publicados há identificação do } \\
\text { profissional }\end{array}$ & 10 & 100,00 & 0 & 0,0 & 10 \\
\hline $\begin{array}{l}16 \text { - Nos sites informativos, } \\
\text { que possuem entrevistas e/ou } \\
\text { artigos publicados há CRM do } \\
\text { profissional }\end{array}$ & 3 & 30,0 & 7 & 70,0 & 10 \\
\hline $\begin{array}{l}17 \text { - Nos sites informativos que } \\
\text { possuem entrevistas e/ou artigos } \\
\text { publicados há divulgação de en- } \\
\text { dereços/telefones de consultórios } \\
\text { nas entrevistas do profissional }\end{array}$ & 4 & 40,0 & 6 & 60,0 & 10 \\
\hline
\end{tabular}


Gráfico 1 - Divisão dos grupos A (sites que seguem as normas do Codame) e B (sites que não as seguem) em relação a cada critério investigado, de outubro de 2008 a julho de 2009. $N=200$

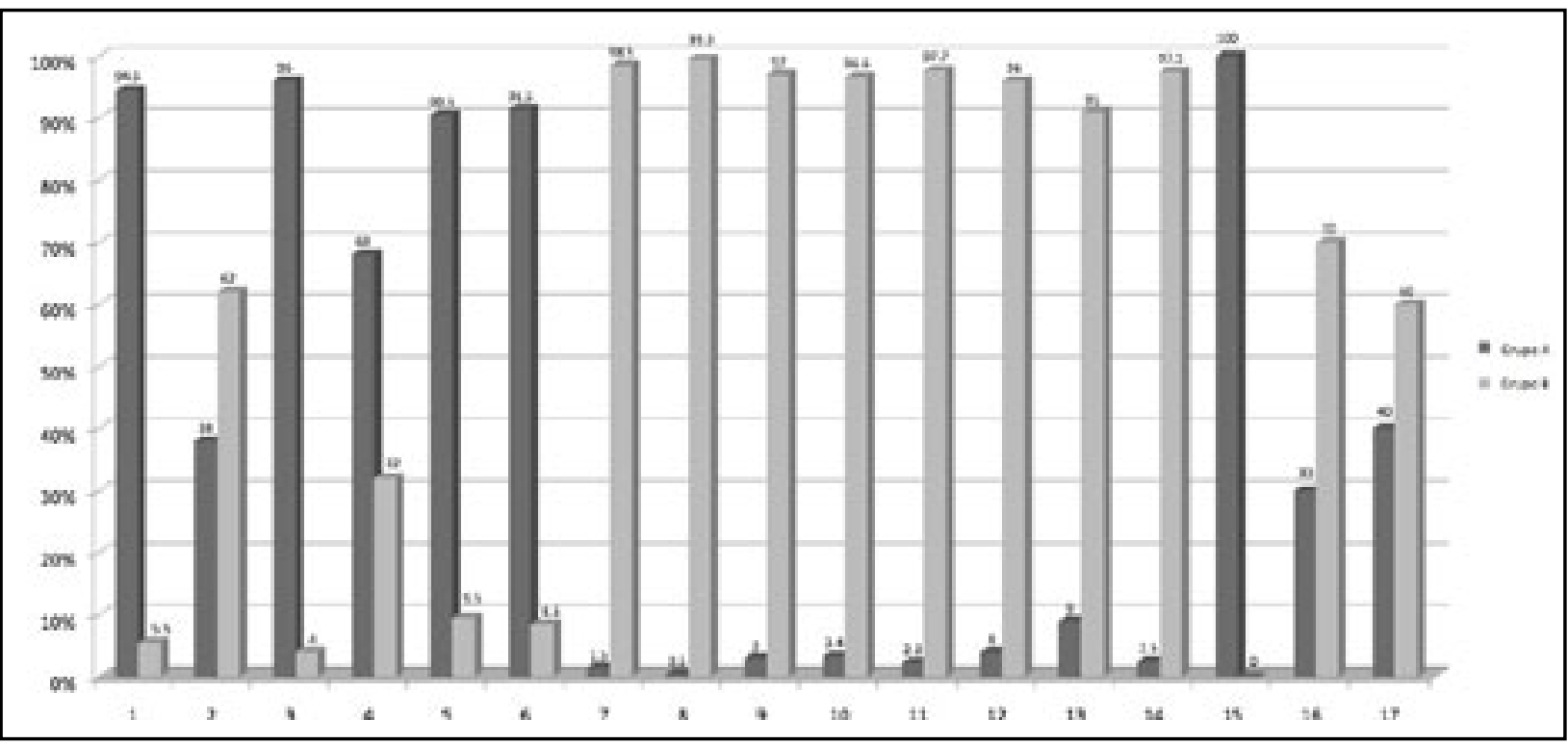

Todos os resultados foram estatisticamente significativos quando comparadas as proporções de sites que seguem as normas (grupo $A$ ) com as proporções de sites que não seguem as normas (grupo B) - (teste de uma proporção; $p$-valores $<0,001$ ). A proporção de sites que não seguem as normas foi superior para a avaliação 2 (presença de número do CRM).

Segundo este estudo, as áreas médicas que mais utilizaram a internet como meio de propaganda no Estado de São Paulo, no período de outubro de 2008 a julho de 2009 foram: cirurgia plástica $(12 \%)$, ginecologia $(8 \%)$, dermatologia $(7 \%)$, endocrinologia $(6 \%)$ e ortopedia $(5 \%)$.

Realizou-se a construção do gráfico de Pareto, apresentado no gráfico 2, com as especialidades médicas que mais utilizaram a internet para veicular suas propagandas no Estado de São Paulo, no período de outubro de 2008 a julho de 2009.

Gráfico 2 - especialidades médicas que utilizaram a internet para veicular suas propagandas no Estado de São Paulo - outubro de 2008 a julho de 2009. N=200

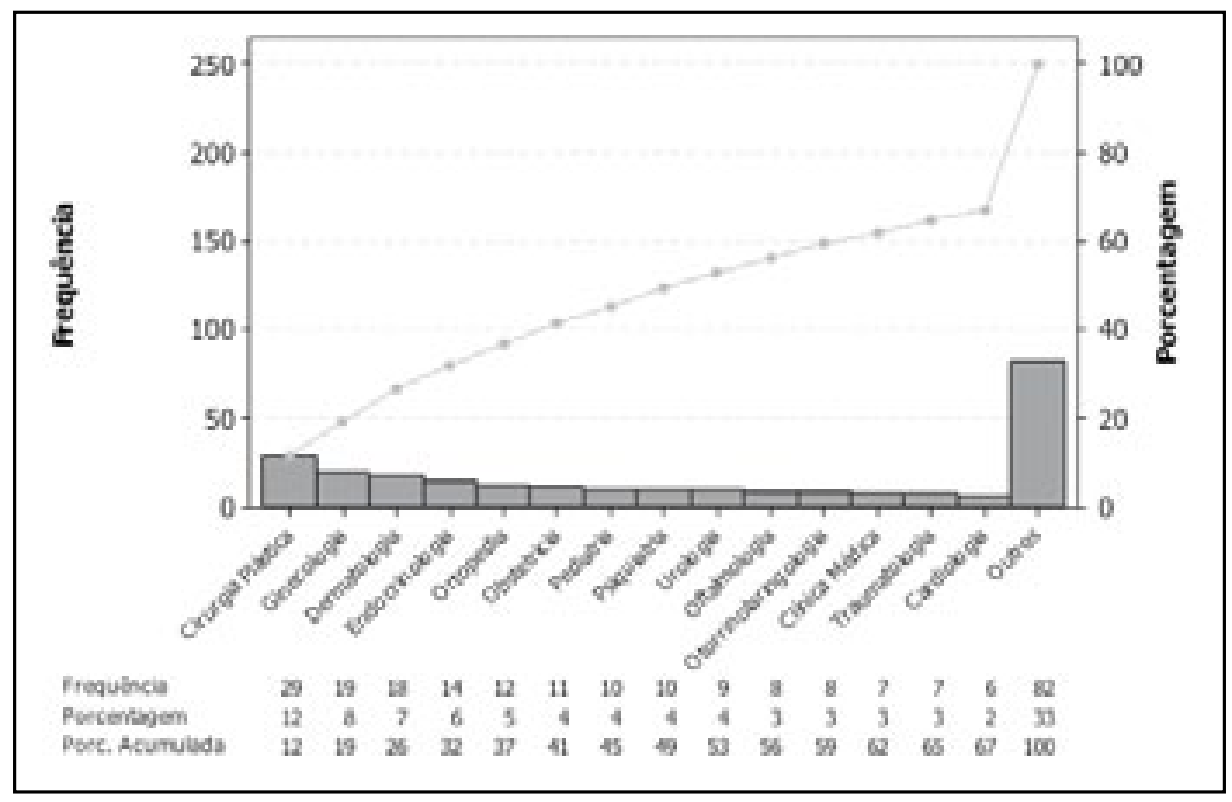


Os pontos positivos que podem ser destacados da utilização da internet para realização das propagandas médicas são:

- Facilidade de divulgação de esclarecimentos, descobertas, novas técnicas e/ou tratamentos, fundamentados em dados técnicos e científicos.

- Veiculação de novos conhecimentos, com o propósito educativo da coletividade.

- Informação para a população sobre aspectos relacionados à prevenção de enfermidades.

- $\quad$ Fornecimento de subsídios para avaliação das opções de tratamento e tomada de decisões.

- Facilidade de obtenção de informações a respeito de determinada especialidade médica.

- Facilidade de contato com o médico através de endereço, telefone, inclusive nos grandes centros urbanos, onde é mais difícil de o profissional se tornar-se conhecido.

Por outro, lados os pontos negativos a serem destacados da utilização da internet para realização das propagandas médicas são:

- Divulgação de informações sobre assuntos médicos de forma sensacionalista ou de conteúdo inverídico.

- Utilização da internet para autopromoção no sentido de aumentar sua clientela.

- Fazer concorrência desleal, como promoções no valor de consultas e cirurgias.

- $\quad$ Pleiteio de exclusividade de métodos diagnósticos ou terapêuticos.

- Utilização da internet para realização de propaganda de determinado produto, equipamento ou medicamento, em troca de vantagem econômica.

- $\quad$ Promoção de exposição dos pacientes por meio de relatos e fotografias.

- Promoção de mercantilização da relação médico paciente.

De acordo com o Código de Ética Médica aprovado na resolução CFM n. 1.931, de 17 de setembro de 2009 , os artigos infringidos pelos sites médicos pesquisados na internet foram:

\section{Capítulo I - PRINCÍPIOS FUNDAMENTAIS}

IV - Ao médico cabe zelar e trabalhar pelo perfeito desempenho ético da medicina, bem como pelo prestígio e bom conceito da profissão.

IX - A medicina não pode, em nenhuma circunstância ou forma, ser exercida como comércio.

XX - A natureza personalíssima da atuação profissional do médico não caracteriza relação de consumo.

\section{Capítulo III - RESPONSABILIDADE PROFISSIONAL}

É vedado ao médico:

Art. 18. Desobedecer aos acórdãos e às resoluções dos conselhos federal e regionais de medicina ou desrespeitá-los. 


\section{Capítulo VIII - REMUNERAÇÃO PROFISSIONAL}

É vedado ao médico:

Art. 58. O exercício mercantilista da medicina.

\section{Capítulo XIII - PUBLICIDADE MÉDICA}

É vedado ao médico:

Art. 111. Permitir que sua participação na divulgação de assuntos médicos, em qualquer meio de comunicação de massa, deixe de ter caráter exclusivamente de esclarecimento e educação da sociedade. Art. 112. Divulgar informação sobre assunto médico de forma sensacionalista, promocional ou de conteúdo inverídico.

Art. 117. Apresentar como originais quaisquer ideias, descobertas ou ilustrações que na realidade não o sejam.

Art. 118. Deixar de incluir, em anúncios profissionais de qualquer ordem, o seu número de inscrição no Conselho Regional de Medicina.

Parágrafo único. Nos anúncios de estabelecimentos de saúde devem constar o nome e o número de registro, no Conselho Regional de Medicina, do diretor técnico.

\section{REFERÊNCIAS FINAIS}

O grande conflito discutido nesta pesquisa foi o compromisso ético, fundamental para o anúncio adequado e que vem sendo substituído por interesses da política socioeconômica capitalista, cujo principal objetivo está centrado na obtenção do lucro. A conquista do mercado por meio da utilização da mídia e, principalmente, da internet, vem se tornando uma constante.

O médico tem legítimo direito de propagar suas atividades profissionais, mas deve conservar-se dentro dos limites éticos. Os médicos que utilizam a internet estão obrigados a seguir as normas do Codame, e a resolução n. 97, de 20/02/2001, do Cremesp (resolução CFM n. 97, 2001).

Os médicos também têm a liberdade de informação disciplinada pelo Código de Ética Médica e devem obediência a uma legislação, civil e criminal, que objetiva tanto fiscalizar como penalizar os que abusam do direito de informar.

É importante prevenir abusos, defendendo a ética na prática médica. Quando o médico se torna responsável pela banalização da medicina, coloca em xeque a relação médico-paciente. $E$ "o alvo de toda a atenção do médico é a saúde do ser humano, em benefício da qual deverá agir com o máximo de zelo e o melhor de sua capacidade profissional". A consequência da destrui- 
ção da relação médico-paciente é a formação de uma mentalidade tecnicista. O médico passa a encarar o corpo humano como uma máquina, e suas desordens (as doenças), como situações decorrentes de desarranjos anatômicos, fisiológicos ou bioquímicos, de origem genética ou adquirida, passíveis de uma abordagem terapêutica voltada ao organismo físico. Por outro lado, o paciente deixa de participar ativamente do processo de reabilitação e o conceito de saúde, que está relacionado ao bem-estar físico, psíquico e social, é negligenciado.

Neste ponto percebe-se que se está diante de uma situação que deve ser combatida em sua essência, pois corre-se o risco de as entidades e a maioria da classe médica sofrer graves consequências com a mercantilização da medicina praticada por alguns profissionais que não firmam seu compromisso com o ser humano e com a ética.

A medicina, uma ciência milenar, não deve ser banalizada e desrespeitada, sob o risco de se colocar em xeque a relação médico-paciente.

Há que se considerar o juramento de Hipócrates: "Ter seus filhos por meus próprios irmãos; ensinar-lhes esta arte se eles tiverem necessidade de aprendê-la, sem remuneração e nem compromisso escrito; fazer participar dos preceitos, das lições e de todo o resto do ensino, meus filhos, os de meu mestre e os discípulos inscritos segundo os regulamentos da profissão, porém, só a estes".

\section{REFERÊNCIAS}

ALCÂNTARA, Hermes Rodrigues de. Normas legais e éticas para o exercício da medicina. São Paulo: LTr Editora, 1984.

ANTUNES, Elton; FRANÇA, Vera Veiga. Médicos, medicina e as operações dos meios de comunicação. In: PETROIANU, Andy (Org.). Ética, moral e deontologia médicas. Rio de Janeiro: Guanabara Koogan, 2000.

BRASIL. Lei n. 8.078, de 11 de setembro de 1990. Código de Defesa do Consumidor. Diário Oficial da República Federativa do Brasil, Brasília, 19 set. 1990. Disponível em:

<www.planalto.gov.br/ccivil_03/LEIS/L8078.htm>. Acesso em: 15 abr. 2008.

Lei n. 4.680, de 18 de junho de 1965. Dispõe sobre o exercício da profissão de publicitário e de agenciador de propaganda e dá outras providências. Diário Oficial da República Federativa do Brasil, Brasília, 21 jun. 1965.

CAMARIM, Lavínio Nilton Compromisso do Cremesp com a prevenção. In: CAMARIM, Lavínio Nilton; MACHADO, Maria Luiza R. de Andrade; DAVID, Marcos (Org.). Ética em publicidade médica. São Paulo: Conselho Regional de Medicina do Estado de São Paulo, 2006. 
CFM - Conselho Federal de Medicina. Resolução CFM n. 1.701, de 25 de setembro de 2003. Diário Oficial da União, Brasília, Poder Executivo, n. 187, 26 set. 2003. Seção 1.

Código de ética médica. Resolução n. 1.246/88, de 08 janeiro de 1988. Diário Oficial da União, Brasília, Poder Executivo, 26 jan. 1988.

CONAR - Conselho Nacional de Autorregulamentação publicitária. Código Brasileiro de Autorregulamentação Publicitária. São Paulo, 1978. Disponível em: <www.conar.org.br/html/codigos/indexcodigoseanexo.htm>. Acesso em: 20 abr. 2008.

CREMA, Roberto. Saúde e plenitude: um caminho para o ser. São Paulo: Summus, 1995.

CREMESP - Conselho Regional de Medicina do Estado de São Paulo. Ética em publicidade médica. São Paulo, 2006. Disponível em: <http://www.cremesp.org.br/library/modulos/publicacoes/pdf/manual_do_Codame_2_Ed_Site.pdf>. Acesso em: 10 abr. 2008.

Resolução CFM n. 97, de 20 de fevereiro de 2001. Diário Oficial do Estado; Seção 1, Poder Executivo, São Paulo, n. 45, 9 mar. 2001.

. Resolução CFM n. 1.036, de 21 de novembro de 1980. Estabelece normas a respeito de anúncios. Diário Oficial da União, Brasília, Poder Executivo, 27 jan. 1981. Seção 1, parte II. Revogada pela Resolução CFM n. 1701/2003.

FAVERO, Flaminio. Noções de deontologia médica e medicina profissional. Rio de Janeiro: Bibliotheca Scientifica Brasileira, 1930.

MACHADO, Maria Luiza R. de Andrade. Responsabilidade na publicidade médica. In: CAMARIM, Lavínio Nilton; MACHADO, Maria Luiza R. de Andrade; DAVID, Marcos (Org.). Ética em publicidade médica. São Paulo: Conselho Regional de Medicina do Estado de São Paulo, 2006.

MOTA, Myriam Becho; BRAICK, Patricia R. História das cavernas ao terceiro milênio. São Paulo: Editora Moderna, 1997.

PERCHE, Moacyr Esteves. Internet e publicidade médica. In: CAMARIM, Lavínio Nilton; MACHADO, Maria Luiza R. de Andrade; DAVID, Marcos (Org.). Ética em publicidade médica. São Paulo: Conselho Regional de Medicina do Estado de São Paulo, 2006.

PEREIRA FILHO, Antonio. Aspectos Positivos da Publicidade Médica. In: CAMARIM, Lavínio Nilton; MACHADO, Maria Luiza R. de Andrade; DAVID, Marcos (Org.). Ética em publicidade médica. São Paulo: Conselho Regional de Medicina do Estado de São Paulo, 2006.

SILVA, Vitor M. C. Ferreira da. A relação médico-paciente. São Paulo, 2001. Disponível em: <http://sab.org.br/med-terap/ art-vitor.htm>. Acesso em: 20 abr. 2008. 
SIMONELI, Osvaldo Pires. O sensacionalismo na atividade médica. In: CAMARIM, Lavínio Nilton; MACHADO, Maria Luiza R. de Andrade; DAVID, Marcos (Org.). Ética em publicidade médica. São Paulo: Conselho Regional de Medicina do Estado de São Paulo, 2006.

SOUSA, Paulo Roberto. Os sentidos do sintoma. Campinas: Papirus, 1992.

SOUSA, Paulo Roberto; VALVASORI, Alquemes; VON ZUBEN, Maria Cristina (Org.). Elementos da bioética. Campinas: Editorial Psy, 1998.

WMA - World Medical Association. Código Internacional de Ética Médica da Associação Médica Mundial. Londres, 1949. Disponível em: <http://www.ordemdosmedicos.cv/index.php?option=com_docman\&task=doc_view\&gid=4>.

Recebido em: 26.02.2012 / Aceito em: 19.04.2012 